\title{
Influence of HIV and HCV on T cell antigen presentation and challenges in the development of vaccines
}

\author{
Mina John ${ }^{1,2}$ and Silvana Gaudieri ${ }^{1,3}$ * \\ ${ }^{1}$ Institute for Immunology and Infectious Diseases, Murdoch University, Murdoch, WA, Australia \\ 2 Department of Clinical Immunology, PathWest Laboratory Medicine WA, Royal Perth Hospital, Perth, WA, Australia \\ ${ }^{3}$ School of Anatomy, Physiology and Human Biology, University of Western Australia, Crawley, WA, Australia
}

\section{Edited by:}

Eric J. Gowans, The University of

Adelaide, Australia

Reviewed by:

Joseph Torresi, University of

Melbourne, Australia

Andrew R. Lloyd, University of New

South Wales, Australia

*Correspondence:

Silvana Gaudieri, School of Anatomy Physiology and Human Biology,

University of Western Australia,

Stirling Highway, Crawley, WA 6009,

Australia

e-mail: silvana.gaudieri@uwa.edu.au
Some of the central challenges for developing effective vaccines against HIV and hepatitis $\mathrm{C}$ virus $(\mathrm{HCV})$ are similar. Both infections are caused by small, highly mutable, rapidly replicating RNA viruses with the ability to establish long-term chronic pathogenic infection in human hosts. HIV has caused 60 million infections globally and HCV 180 million and both viruses may co-exist among certain populations by virtue of common blood-borne, sexual, or vertical transmission. Persistence of both pathogens is achieved by evasion of intrinsic, innate, and adaptive immune defenses but with some distinct mechanisms reflecting their differences in evolutionary history, replication characteristics, cell tropism, and visibility to mucosal versus systemic and hepatic immune responses. A potent and durable antibody and $T$ cell response is a likely requirement of future HIV and HCV vaccines. Perhaps the single biggest difference between the two vaccine design challenges is that in $\mathrm{HCV}$, a natural model of protective immunity can be found in those who resolve acute infection spontaneously. Such spontaneous resolvers exhibit durable and functional $\mathrm{CD} 4^{+}$and $\mathrm{CD} 8^{+}$ T cell responses (Diepolder et al., 1995; Cooper et al., 1999; Thimme et al., 2001; Grakoui etal., 2003; Lauer etal., 2004; Schulze Zur Wiesch etal., 2012). However, frequent reinfection suggests partial or lack of protective immunity against heterologous HCV strains, possibly indicative of the degree of genetic diversity of circulating HCV genotypes and subtypes. There is no natural model of protective immunity in HIV, however, studies of "elite controllers," or individuals who have durably suppressed levels of plasma HIV RNA without antiretroviral therapy, has provided the strongest evidence for $\mathrm{CD}^{+} \mathrm{T}$ cell responses in controlling viremia and limiting reservoir burden in established infection. Here we compare and contrast the specific mechanisms of immune evasion used by HIV and $\mathrm{HCV}$, which subvert adaptive human leukocyte antigen (HLA)-restricted T cell immunity in natural infection, and the challenges these pose for designing effective preventative or therapeutic vaccines.

Keywords: HIV, HCV, viral immune escape, preventative vaccine, anti-viral immune responses

\section{LEADS FROM GENETIC ASSOCIATION STUDIES SUPPORT IMPORTANCE OF IMMUNOLOGICAL MECHANISMS IN VIRAL INFECTION OUTCOME}

Genetic determinants of spontaneous HCV infection clearance and HIV viral control using genome-wide association studies (GWAS) and candidate gene studies have added crucial insight into the influence of the host immune response on infection outcome. For HIV the strongest genetic determinant of viral load set-point and $\mathrm{CD}^{+} \mathrm{T}$ cell decline following infection, aside from variants in the CCR5 molecule used by HIV for cell entry, are specific HLA class I alleles (e.g., HLA-B27 and HLA-B57; reviewed in O'Brien et al., 2001) involved in T cell antigen presentation. More recently, a GWAS has shown the association of HLA-C with viral control (International HIVCS et al., 2010). The variation at HLA-C associated with HIV outcome appears to affect cell surface expression of the HLA molecule (Thomas et al., 2009b). The HLA class I molecules also act as ligands for natural killer (NK) cell receptors and this interaction is known to influence the activation threshold for NK cells. Particular combinations of killer immunoglobulinlike receptors (KIR) and HLA class I ligands are strongly associated with HIV infection outcome (Martin et al., 2002).

For HCV, studies that examine host genetic associations with infection outcome clearly indicate that genotypic differences in the interferon pathway such as interferon lambda 3 (IFN- $\lambda 3$ ) (Thomas et al., 2009a; Rauch et al., 2010), NK cell cytotoxicity activation threshold (Khakoo et al., 2004) and specific HLA class I and II alleles (McKiernan et al., 2004; Miki et al., 2013) are strongly associated with resolution following HCV infection (reviewed in Rauch et al., 2009a).

For both HIV and HCV, the genetic leads support the involvement of $\mathrm{CD}^{+} \mathrm{T}$ cells and antigen presentation in infection outcome. Further evidence can be obtained from the observed heterozygote advantage at the HLA loci for both viral infections (Carrington et al., 1999; Hraber et al., 2007), likely reflecting the presentation of an increased number of $\mathrm{T}$ cell targets. 


\section{VIRAL EFFECTS ON ANTIGEN PRESENTATION}

To establish chronic infection, viruses such as HIV and HCV must evade the host's T cell response. The host's T cell response is governed by the assembly and presentation of antigen via the polymorphic HLA class I and II molecules. In the case of HLA class I presentation of viral peptides to $\mathrm{CD} 8^{+}$cytotoxic $\mathrm{T}$ cells (CTL), the process requires correct folding of the HLA class I molecules with b2-microglobulin in the endoplasmic reticulum. In parallel, the viral peptides that have been processed by the proteasome complex in the cytosol are then loaded onto the HLA class I- $\beta 2$-microglobulin complex via the transporter associated with antigen presentation (TAP) protein. This tertiary structure is then translocated to the surface of the cell via the golgi apparatus for presentation to a CTL with the appropriate T cell receptor. Both HIV and HCV have evolved several mechanisms to disrupt this pathway including reduction of HLA class I expression and mutational escape from antigen presentation.

\section{EFFECTS ON HLA EXPRESSION}

For HCV, the proteins core (Miyamoto et al., 2007) and NS3 (Khu et al., 2004) have been shown to affect the function of the proteasome complex (reviewed in Osna, 2009) and potentially HLA class I presentation. Other evidence from the Huh-7 subgenomic replicon system, suggests that $\mathrm{HCV}$ infection reduces HLA class I surface expression via a stress-mediated mechanism that lowers the efficacy of HLA class I folding in the endoplasmic reticulum, although the mechanism does not appear to be specific for HLA class I molecules (Tardif and Siddiqui, 2003). However, another study by Herzer et al. (2003) utilizing liver cell lines and plasmid constructs showed increased HLA class I expression via the action of the HCV core protein on TAP1 (function is dependent on p53). Interestingly, increased HLA class I expression was only seen in HepG2 cells (contain functional p53) and not in Huh-7 cells (exhibit a non-functional p53), not for HLA class II (using a pan HLA-DR antibody) and not for other HCV proteins used in a plasmid construct. However, the change in HLA class I expression on the HepG2 cells did not appear to affect $\mathrm{CD} 8^{+} \mathrm{T}$ cell recognition and may instead be related to NK cell cytotoxicity.

The ability to differentiate the effect of HCV on the expression of the different HLA class I loci will be critical given the differing functions/interactions of HLA-A, $-\mathrm{B}$, and -C alleles with NK cell receptors and potentially $\mathrm{CD}^{+} \mathrm{T}$ cell antigen presentation. It should be noted that in the studies described above, the pan HLA-class I antibody W6/32 was used and this antibody does not differentiate between the HLA class I loci.

Interactions between HIV and HLA surface expression are well established. HIV Nef in particular down-modulates cell surface expression of HLA-A and -B molecules, rendering them less visible to cytotoxic $\mathrm{CD}^{+} \mathrm{T}$ cells, however HLA-C and -E are not selectively down-modulated, which renders them resistant to NKmediated lysis (Cohen et al., 1999). More recently, differential expression levels of different HLA-C alleles mediated through micro-RNA regulation were found to be important in influencing HIV-1 control. Increased cell surface expression levels of HLA-C were significantly associated with reduced longitudinal viral load and rate of decline in $\mathrm{CD} 4^{+} \mathrm{T}$ cell count in a study involving over 5000 individuals with pre-treatment HIV-1 infection (Apps et al.,
2013). Furthermore, this effect was independent of all other HLA allele-specific effects and was robust across different ethnic groups with distinct HLA-C allele frequency distributions and linkage relationships with HLA-A and -B alleles. Further, differential HLA$\mathrm{C}$ expression levels correlated with measured CTL responses and frequency of viral escape mutation, signifying a direct modulatory effect on disease outcome mediated through the quality of HLA-C restricted $\mathrm{T}$ cell responses. While this is a "peptide-independent" mechanism of control, it points to the importance of providing sufficient epitopes for HLA-C in a vaccine immunogen not liable to escape from responses binding with high or low expressing HLA-C alleles.

Human leukocyte antigen class II presentation by antigen presenting cells (APCs) to CD4 ${ }^{+} \mathrm{T}$ cells is important for both HIV and HCV, but less is known about how these viruses affect HLA class II presentation. In general, nascent HLA class II molecules in the endoplasmic reticulum of APCs such as dendritic cells associate with the invariant chain protein, which acts to prevent the binding of endogenous peptides in the HLA class II pocket as well as a chaperone for the HLA class II molecule to the golgi apparatus for transportation to the cell surface. However, cell surface expression of HLA class II molecules is not possible until the invariant chain is degraded by a protease such as cathepsin.

Hepatitis $\mathrm{C}$ virus is known to affect dendritic cell function and maturation and has been shown to inhibit HLA class II (HLA-DR) expression on dendritic cells (Siavoshian et al., 2005; Averill et al., 2007; Saito etal., 2008). Subsequent studies have shown that dendritic cells exposed to HCV exhibit decreased expression of Cathepsin $\mathrm{S}$ with a corresponding decrease of HLA-DR expression on the cell surface, mainly mediated through the HCV proteins core and NS5A (Kim et al., 2012). Interestingly, hepatocytes may act as APCs in the liver and similar interactions were observed when these cells are transfected with core and NS5A (Kim et al., 2012). More should be examined in this area for $\mathrm{HCV}$ as $\mathrm{CD}^{+}$ $\mathrm{T}$ cells are critical in $\mathrm{HCV}$ infection outcome based on $\mathrm{CD} 4^{+} \mathrm{T}$ cell depletion and HLA class II tetramer studies that clearly show lack of CD4 ${ }^{+} \mathrm{T}$ cell help and a collapse in HCV-specific CD4 ${ }^{+} \mathrm{T}$ cell responses within months of acute HCV infection is strongly associated with persistence (Lucas et al., 2007; Schulze Zur Wiesch et al., 2012).

Although less studied compared to interactions with HLA class I, HIV Nef has been shown to influence HLA class II surface expression through effects on intracellular trafficking (StumptnerCuvelette et al., 2001). Notably, slower progression of pediatric HIV disease has been associated with nef variants, which induced greater down-modulation of surface HLA class II expression, possibly through reducing $\mathrm{CD} 4^{+} \mathrm{T}$ cell activation and therefore cell loss (Schindlera et al., 2007).

\section{VIRAL ESCAPE, DIVERSITY AND POPULATION LEVEL ADAPTATION}

HIV and HCV have error-prone polymerases, rapid replication cycles and in the case of HIV high intracellular recombination rate, allowing for rapid generation, and selective outgrowth of mutant strains, which escape antigen-specific antiviral responses mediated by $\mathrm{T}$ cells and NK cells. There is now an extensive literature documenting the predictable mutational networks, which arise in circulating HIV and HCV strains as a result 
of escape from HLA-restricted T cell responses (Moore et al., 2002; Gaudieri etal., 2006; Rauch et al., 2009b). The antigenic diversity, which partly results from this escape mechanism, is extreme compared to other vaccine-preventable virus infections, and therefore requires especially broad-based immunity from vaccines against HIV and HCV. What makes T cell escape particularly notable is that HLA, which mediates the peptide specific targeting of virally infected cells, is the most polymorphic of human gene systems, having become so as a result of myriad microbial selective pressures in human evolution (Prugnolle et al., 2005). To retain or even increase in vivo fitness despite mutation in the context of the great diversity of HLA types across a pandemic infection underscores the plasticity of these viruses and the challenge of vaccinating against them at the population level.

In terms of the diversity challenge for vaccines, among the nine phylogenetically distinct HIV-1 group $M$ subtypes, subtypes C and $\mathrm{B}$ account for the majority of the global epidemic but have as much as $30-40 \%$ inter-subtype diversity at certain segments of the genome. Phylogenetic trees based on HCV sequences indicate the challenge of diversity with HCV, which has an up to 3000-fold higher replication rate than HIV and the absence of any constraint imposed by overlapping open reading frames. HCV genotype 1 is as diverse as all the subtypes of HIV (Figure 1). HCV is classified into seven genotypes that differ by about $20-30 \%$ at the amino acid level and multiple subtypes for each genotype that differ by 10-15\% (Smith et al., 2014). We have previously shown that the polymorphism profile of the different genotypes along sites in the non-structural proteins of HCV vary and supports the observation that there is limited overlap in viral adaptations between genotypes (Rauch et al., 2009b). The limited overlap in the adaptation profile of the genotype 1a and 3a strains likely reflects both different $\mathrm{T}$ cell targets as well as different fitness costs associated with variations at specific sites (Salloum et al., 2008; Dazert et al., 2009).
A multi-epitope approach using non-structural proteins has been successful to elicit effective immunity against heterologous HCV strains suggesting potential for effective vaccine development (Folgori et al., 2006; Lang Kuhs et al., 2012). However, a limitation of vaccines developed for HCV is that the use of a small number of $\mathrm{T}$ cell epitopes are not sufficient to cover the high variability of HCV observed at the population level (Firbas et al., 2006; Klade et al., 2008). A paucity in the number of known HCVspecific HLA-restricted $\mathrm{T}$ cell epitopes is a challenge for a $\mathrm{T}$ cell based HCV vaccine.

A further implication of $\mathrm{T}$ cell escape is the degree to which escape can accumulate over time in viruses circulating in populations, rendering natural, and vaccine-induced $\mathrm{CD}^{+} \mathrm{T}$ cell responses ineffective against transmitting strains, especially those restricted by common HLA alleles. The frequency of certain HLAdriven escape mutations in HIV are highly correlated to HLA allele frequency across ethnically diverse populations, including for some well-known escape networks associated with "protective" HLA alleles (Kawashima et al., 2009). This is an inherently difficult phenomenon to prove, however, as the more such adaptations might accumulate in a population, the less polymorphism and less statistical power to show a correlation with any host trait as evidence of an adaptive process. Notably early population-based studies of HIV and HCV escape detected significant associations between common population HLA alleles and the presence of population consensus amino acids in autologous viruses, which raised the possibility that these were HLA-driven adaptations that had become fixed at the population level (Moore et al., 2002). This clearly has implications for vaccine immunogens, which may include such "population-adapted" areas.

\section{CURRENT VACCINE DEVELOPMENT}

There is recognition of the need to stimulate both arms of the adaptive immune response for an effective preventative HCV vaccine (reviewed in Swadling et al., 2013) and evidence to support

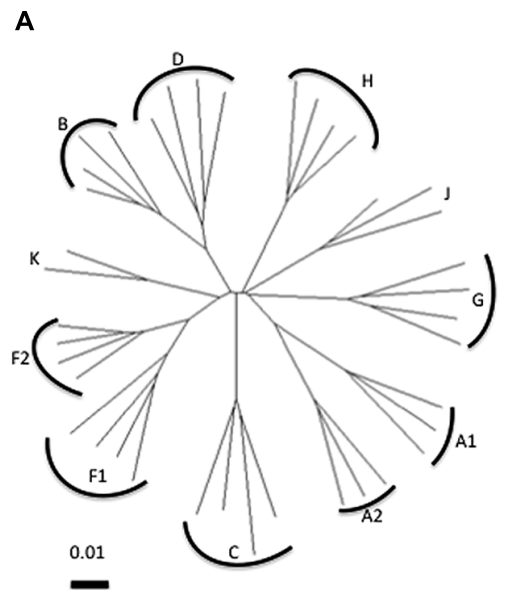

FIGURE 1 | Phylogenetic analysis of (A) HIV pol and (B) HCV NS5B polymerase sequences. Neighbor-joining trees were constructed using the Tamura-Nei model. Note the distance bar for HIV corresponds to 0.01 substitutions per site and for

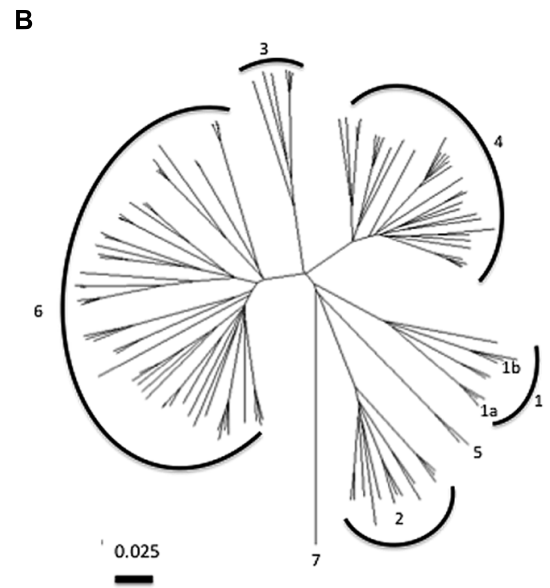

HCV 0.025 substitutions per site. Common HCV subtypes 1a and $1 \mathrm{~b}$ are indicated on tree. HCV subtype and HIV clade sequences obtained from www.hcv.lanl.gov and www.hiv.lanl.gov, respectively. 
the inclusion of both structural and non-structural proteins (reviewed in Torresi et al., 2011). Previous studies have shown evidence of cross-reactive neutralizing antibodies (NAbs), particularly in the chimpanzee model (Choo etal., 1994; Forns et al., 2000; Rollier et al., 2007; Meunier et al., 2011), but limited data on vaccine candidates that elicit both NAbs and HCVspecific $\mathrm{T}$ cell responses. Recently, encouraging results have been reported by Martinez-Donato et al. (2014) who utilized a mixture of HCV core, E1, E2, and NS3 in Alum (MixprotHC; containing likely conserved $\mathrm{T}$ cell epitopes) from a genotype $1 \mathrm{~b}$ strain to induce cross-reactive IgG NAbs (to genotype 1a and $2 \mathrm{a}$ ) and broad HCV-specific $\mathrm{CD} 4^{+}$and $\mathrm{CD} 8^{+} \mathrm{T}$ cell responses (detected via proliferation and IFN-gamma ELISpot assays) in immunized mice (BALB/c) and African Green Monkeys. Importantly, immunization with MixprotHC also suppresses viremia in a surrogate challenge model in mice. Other vector-based and DNA-based vaccine candidates exist (reviewed in Swadling etal., 2013) and outcomes from Phase II trials should be informative as to their likely efficacy in "at-risk" populations.

In the comparatively much larger and now 30 year old field of HIV vaccine development, the lack of an effective vaccine points to the many remaining barriers to inducing broadly NAbs or effective $\mathrm{CD} 8^{+} \mathrm{T}$ cells capable of acting and persisting at the site of mucosal HIV entry. Many current vaccine strategies progressing to clinical studies seek to address some of the evasion mechanisms discussed here. For example, there has been testing of various diversity-combating immunogen design approaches, including mosaic vaccines in which inclusion of variant epitopes is optimized, as well as strategies based on conserved immunogens sequences. There are numerous adjuvants, vectors and delivery vehicles designed to improve the efficiency of antigen presentation of vaccine antigens in order to stimulate effective antiviral responses. There are two recent vaccine programs, however, which raise the intriguing possibility that vaccines may need to induce mechanisms of antigen presentation that are highly distinct from those seen in natural infection for their protective effects. A novel "tolerogenic" vaccine consisting of inactivated simian immunodeficiency virus (SIV) mac239 particles with particular bacterial adjuvants has been shown to elicit $\mathrm{CD} 8^{+} \mathrm{T}$-regulatory cells in vaccinated macaques. These $\mathrm{T}$ cell were not cytolytic but were able to suppress the activation of SIV-positive $\mathrm{CD} 4^{+} \mathrm{T}$ cells, rendering them less susceptible to SIV infection after challenge. In addition, these $\mathrm{CD} 8^{+} \mathrm{T}$ cells were found to be uniquely restricted by non-classical MHCIb/E molecules (Andrieu et al., 2014), corresponding to HLA-E in humans. Interestingly, recent data shows HLA-E expression in liver biopsies correlates with HCV viral load in chronic HCV-infected subjects and NK cells lacking the inhibitory receptor for HLA-E (NKG2A) is associated with protection from HCV infection in high-risk exposure subjects (Thoens et al., 2014). To date there has been no examination of non-classical HLA-restricted $\mathrm{CD}^{+}{ }^{+} \mathrm{T}$ cells in $\mathrm{HCV}$ infection. In contrast to the $\mathrm{CD} 8{ }^{+}$"T-regulatory" type cells described above, a vaccine based on a rhesis $\mathrm{CMV}$ vector has produced durable protection or clearance of SIV challenge infections in vaccinated macaques associated with induction of effector memory $\mathrm{CD} 8^{+} \mathrm{T}$ cell responses. However, these $\mathrm{CD}^{+} \mathrm{T}$ cells have been found to target a diverse array of promiscuous or dominant epitopes restricted by HLA class II alleles, rather than HLA class I (Hansen et al., 2013). In both these examples, properties of the vaccine appear to violate the usual rules of $\mathrm{CD}^{+} \mathrm{T}$ cell priming and both show promising efficacy in the SIV-macaque model, suggesting novel ways in which vaccines may avoid the evolutionary solutions that SIV/HIV may have developed in natural infection.

\section{CONCLUSION}

In general, induction of $\mathrm{CD}^{+}$and $\mathrm{CD}^{+} \mathrm{T}$ cell responses a key aim of most current vaccine candidates for HIV and HCV, together with innate and humoral immunity as part of a coordinated and long lived immune response. For preventative vaccines, the efficacy of $\mathrm{CD}^{+}{ }^{+}$and $\mathrm{CD} 8^{+} \mathrm{T}$ cells will crucially depend on the extent to which the vaccine induced $\mathrm{T}$ cells can overcome natural effects of these viruses on HLA expression, antigen presentation and HLA-associated viral diversity.

\section{REFERENCES}

Andrieu, J. M., Chen, S., Lai, C., Guo, W., and Lu, W. (2014). Mucosal SIV vaccines comprising inactivated virus particles and bacterial adjuvants induce CD8(+) T-regulatory cells that suppress SIV-positive CD4(+) T-cell activation and prevent SIV infection in the Macaque Model. Front. Immunol. 5:297. doi: 10.3389/fimmu.2014.00297

Apps, R., Qi, Y., Carlson, J. M., Chen, H., Gao, X., Thomas, R., et al. (2013). Influence of HLA-C expression level on HIV control. Science 340, 87-91. doi: 10.1126/science. 1232685

Averill, L., Lee, W. M., and Karandikar, N. J. (2007). Differential dysfunction in dendritic cell subsets during chronic HCV infection. Clin. Immunol. 123, 40-49. doi: 10.1016/j.clim.2006.12.001

Carrington, M., Nelson, G. W., Martin, M. P., Kissner, T., Vlahov, D., Goedert, J. J., et al. (1999). HLA and HIV-1: heterozygote advantage and B ${ }^{\star} 35-\mathrm{Cw}^{\star} 04$ disadvantage. Science 283, 1748-1752. doi: 10.1126/science.283.5408.1748

Choo, Q. L., Kuo, G., Ralston, R., Weiner, A., Chien, D., Van Nest, G., et al. (1994). Vaccination of chimpanzees against infection by the hepatitis C virus. Proc. Natl. Acad. Sci. U.S.A. 91, 1294-1298. doi: 10.1073/pnas.91.4.1294

Cohen, G. B., Gandhi, R. T., Davis, D. M., Mandelboim, O., Chen, B. K., Strominger, J. L., et al. (1999). The selective downregulation of class I major histocompatibility complex proteins by HIV-1 protects HIV-infected cells from NK cells. Immunity 10, 661-671. doi: 10.1016/S1074-7613(00)80065-5

Cooper, S., Erickson, A. L., Adams, E. J., Kansopon, J., Weiner, A. J., Chien, D. Y., et al. (1999). Analysis of a successful immune response against hepatitis $C$ virus. Immunity 10, 439-449. doi: 10.1016/S1074-7613(00)80044-8

Dazert, E., Neumann-Haefelin, C., Bressanelli, S., Fitzmaurice, K., Kort, J., Timm, J., et al. (2009). Loss of viral fitness and cross-recognition by $\mathrm{CD}^{+} \mathrm{T}$ cells limit HCV escape from a protective HLA-B27-restricted human immune response. J. Clin. Invest. 119, 376-386. doi: 10.1172/JCI36587

Diepolder, H. M., Zachoval, R., Hoffmann, R. M., Wierenga, E. A., Santantonio, T., Jung, M. C., et al. (1995). Possible mechanism involving T-lymphocyte response to non-structural protein 3 in viral clearance in acute hepatitis $\mathrm{C}$ virus infection. Lancet 346, 1006-1007. doi: 10.1016/S0140-6736(95)91691-1

Firbas, C., Jilma, B., Tauber, E., Buerger, V., Jelovcan, S., Lingnau, K., et al. (2006). Immunogenicity and safety of a novel therapeutic hepatitis $C$ virus (HCV) peptide vaccine: a randomized, placebo controlled trial for dose optimization in 128 healthy subjects. Vaccine 24, 4343-4353. doi: 10.1016/j.vaccine.2006. 03.009

Folgori, A., Capone, S., Ruggeri, L., Meola, A., Sporeno, E., Ercole, B. B., et al. (2006). A T-cell HCV vaccine eliciting effective immunity against heterologous virus challenge in chimpanzees. Nat. Med. 12, 190-197. doi: 10.1038/nm1353

Forns, X., Payette, P. J., Ma, X., Satterfield, W., Eder, G., Mushahwar, I. K., et al. (2000). Vaccination of chimpanzees with plasmid DNA encoding the hepatitis $\mathrm{C}$ virus $(\mathrm{HCV})$ envelope $\mathrm{E} 2$ protein modified the infection after challenge with homologous monoclonal HCV. Hepatology 32, 618-625. doi: 10.1053/jhep. 2000.9877 
Gaudieri, S., Rauch, A., Park, L. P., Freitas, E., Herrmann, S., Jeffrey, G., et al. (2006). Evidence of viral adaptation to HLA class I-restricted immune pressure in chronic hepatitis C virus infection. J. Virol. 80, 11094-11104. doi: 10.1128/JVI. 00912-06

Grakoui, A., Shoukry, N. H., Woollard, D. J., Han, J. H., Hanson, H. L., Ghrayeb, J., et al. (2003). HCV persistence and immune evasion in the absence of memory $\mathrm{T}$ cell help. Science 302, 659-662. doi: 10.1126/science.1088774

Hansen, S. G., Sacha, J. B., Hughes, C. M., Ford, J. C., Burwitz, B. J., Scholz, I., et al. (2013). Cytomegalovirus vectors violate $\mathrm{CD}^{+} \mathrm{T}$ cell epitope recognition paradigms. Science 340, 1237874. doi: 10.1126/science.1237874

Herzer, K., Falk, C. S., Encke, J., Eichhorst, S. T., Ulsenheimer, A., Seliger, B., et al. (2003). Upregulation of major histocompatibility complex class I on liver cells by hepatitis $\mathrm{C}$ virus core protein via p53 and TAP1 impairs natural killer cell cytotoxicity. J. Virol. 77, 8299-8309. doi: 10.1128/JVI.77.15.82998309.2003

Hraber, P., Kuiken, C., and Yusim, K. (2007). Evidence for human leukocyte antigen heterozygote advantage against hepatitis $\mathrm{C}$ virus infection. Hepatology 46, 1713 1721. doi: 10.1002/hep. 21889

International HIVCS, Pereyra, F., Jia, X., McLaren, P. J., Telenti, A., de Bakker P. I., et al. (2010). The major genetic determinants of HIV-1 control affect HLA class I peptide presentation. Science 330, 1551-1557. doi: 10.1126/science. 1195271

Kawashima, Y., Pfafferott, K., Frater, J., Matthews, P., Payne, R., Addo, M., et al. (2009). Adaptation of HIV-1 to human leukocyte antigen class I. Nature 458 641-645. doi: 10.1038/nature07746

Khakoo, S. I., Thio, C. L., Martin, M. P., Brooks, C. R., Gao, X., Astemborski, J., et al. (2004). HLA and NK cell inhibitory receptor genes in resolving hepatitis $\mathrm{C}$ virus infection. Science 305, 872-874. doi: 10.1126/science.1097670

Khu, Y. L., Tan, Y. J., Lim, S. G., Hong, W., and Goh, P. Y. (2004). Hepatitis C virus non-structural protein NS3 interacts with LMP7, a component of the immunoproteasome, and affects its proteasome activity. Biochem. J. 384(Pt 2), 401-409. doi: 10.1042/BJ20040858

Kim, H., Mazumdar, B., Bose, S. K., Meyer, K., Di Bisceglie, A. M., Hoft, D. F., et al. (2012). Hepatitis $C$ virus-mediated inhibition of cathepsin $S$ increases invariant-chain expression on hepatocyte surface. J. Virol. 86, 9919-9928. doi 10.1128/JVI.00388-12

Klade, C. S., Wedemeyer, H., Berg, T., Hinrichsen, H., Cholewinska, G., Zeuzem S., et al. (2008). Therapeutic vaccination of chronic hepatitis $C$ nonresponder patients with the peptide vaccine IC41. Gastroenterology 134, 1385-1395. doi: 10.1053/j.gastro.2008.02.058

Lang Kuhs, K. A., Ginsberg, A. A., Yan, J., Wiseman, R. W., Khan, A. S., Sardesai, N. Y., et al. (2012). Hepatitis C virus NS3/NS4A DNA vaccine induces multiepitope $\mathrm{T}$ cell responses in rhesus macaques mimicking human immune responses [corrected]. Mol. Ther. 20, 669-678. doi: 10.1038/mt.2011.188

Lauer, G. M., Barnes, E., Lucas, M., Timm, J., Ouchi, K., Kim, A. Y., et al. (2004). High resolution analysis of cellular immune responses in resolved and persistent hepatitis C virus infection. Gastroenterology 127, 924-936. doi: 10.1053/j.gastro.2004.06.015

Lucas, M., Ulsenheimer, A., Pfafferot, K., Heeg, M. H., Gaudieri, S., Gruner, N., et al. (2007). Tracking virus-specific $\mathrm{CD} 4^{+} \mathrm{T}$ cells during and after acute hepatitis C virus infection. PLoS ONE. 2:e649. doi: 10.1371/journal.pone. 0000649

Martin, M. P., Gao, X., Lee, J. H., Nelson, G. W., Detels, R., Goedert, J. J., et al. (2002). Epistatic interaction between KIR3DS1 and HLA-B delays the progression to AIDS. Nat. Genet. 31, 429-434. doi: 10.1038/ng934

Martinez-Donato, G., Amador-Canizares, Y., Alvarez-Lajonchere, L., Guerra, I., Perez, A., Dubuisson, J., et al. (2014). Neutralizing antibodies and broad, functional $\mathrm{T}$ cell immune response following immunization with hepatitis $\mathrm{C}$ virus proteins-based vaccine formulation. Vaccine 32, 1720-1726. doi: 10.1016/j.vaccine.2014.01.046

McKiernan, S. M., Hagan, R., Curry, M., McDonald, G. S., Kelly, A., Nolan, N., et al. (2004). Distinct MHC class I and II alleles are associated with hepatitis C viral clearance, originating from a single source. Hepatology 40, 108-114. doi: 10.1002/hep.20261

Meunier, J. C., Gottwein, J. M., Houghton, M., Russell, R. S., Emerson, S. U., Bukh, J., et al. (2011). Vaccine-induced cross-genotype reactive neutralizing antibodies against hepatitis C virus. J. Infect. Dis. 204, 1186-1190. doi: 10.1093/infdis/ jir511
Miki, D., Ochi, H., Takahashi, A., Hayes, C. N., Urabe, Y., Abe, H., et al. (2013). HLADQB1 ${ }^{\star} 03$ confers susceptibility to chronic hepatitis C in Japanese: a genome-wide association study. PLoS ONE 8:e84226. doi: 10.1371/journal.pone.0084226

Miyamoto, H., Moriishi, K., Moriya, K., Murata, S., Tanaka, K., Suzuki, T., et al. (2007). Involvement of the PA28gamma-dependent pathway in insulin resistance induced by hepatitis C virus core protein. J. Virol. 81, 1727-1735. doi: 10.1128/JVI.01683-06

Moore, C. B., John, M., James, I. R., Christiansen, F. T., Witt, C. S., and Mallal, S. A. (2002). Evidence of HIV-1 adaptation to HLA-restricted immune responses at a population level. Science 296, 1439-1443. doi: 10.1126/science.1069660

O’Brien, S. J., Gao, X., and Carrington, M. (2001). HLA and AIDS: a cautionary tale. Trends Mol. Med. 7, 379-381. doi: 10.1016/S1471-4914(01)02131-1

Osna, N. A. (2009). Hepatitis C virus and ethanol alter antigen presentation in liver cells. World J. Gastroenterol. 15, 1201-1208. doi: 10.3748/wjg.15.1201

Prugnolle, F., Manica, A., Charpentier, M., Guegan, J. F., Guernier, V., and Balloux, F. (2005). Pathogen-driven selection and worldwide HLA class I diversity. Curr. Biol. 15, 1022-1027. doi: 10.1016/j.cub.2005.04.050

Rauch, A., Gaudieri, S., Thio, C., and Bochud, P. Y. (2009a). Host genetic determinants of spontaneous hepatitis C clearance. Pharmacogenomics 10, 1819-1837. doi: 10.2217/pgs.09.121

Rauch, A., James, I., Pfafferott, K., Nolan, D., Klenerman, P., Cheng, W., et al. (2009b). Divergent adaptation of hepatitis $C$ virus genotypes 1 and 3 to human leukocyte antigen-restricted immune pressure. Hepatology 50, 1017-1029. doi: 10.1002/hep.23101

Rauch, A., Kutalik, Z., Descombes, P., Cai, T., Di Iulio, J., Mueller, T., et al. (2010) Genetic variation in IL28B is associated with chronic hepatitis C and treatment failure: a genome-wide association study. Gastroenterology 138, 1338-1345, 1345.e1-1345.e7. doi: 10.1053/j.gastro.2009.12.056

Rollier, C. S., Paranhos-Baccala, G., Verschoor, E. J., Verstrepen, B. E., Drexhage, J. A., Fagrouch, Z., et al. (2007). Vaccine-induced early control of hepatitis C virus infection in chimpanzees fails to impact on hepatic PD-1 and chronicity. Hepatology 45, 602-613. doi: 10.1002/hep. 21573

Saito, K., Ait-Goughoulte, M., Truscott, S. M., Meyer, K., Blazevic, A., Abate, G., et al. (2008). Hepatitis C virus inhibits cell surface expression of HLA-DR, prevents dendritic cell maturation, and induces interleukin-10 production. J. Virol. 82, 3320-3328. doi: 10.1128/JVI.02547-07

Salloum, S., Oniangue-Ndza, C., Neumann-Haefelin, C., Hudson, L., Giugliano, S., aus dem Siepen, M., et al. (2008). Escape from HLA-B ${ }^{\star} 08$-restricted CD8 T cells by hepatitis $\mathrm{C}$ virus is associated with fitness costs. J. Virol. 82, 11803-11812. doi: 10.1128/JVI.00997-08

Schindlera, M., Wilduma, S., Casartellib, N., Doriab, M., and Kirchhoff, F. (2007). Nef alleles from children with non-progressive HIV-1 infection modulate MHC-II expression more efficiently than those from rapid progressors. AIDS 21, $1103-$ 1107. doi: 10.1097/QAD.0b013e32816aa37c

Schulze Zur Wiesch, J., Ciuffreda, D., Lewis-Ximenez, L., Kasprowicz, V., Nolan, B. E., Streeck, H., et al. (2012). Broadly directed virus-specific $\mathrm{CD} 4^{+} \mathrm{T}$ cell responses are primed during acute hepatitis $\mathrm{C}$ infection, but rapidly disappear from human blood with viral persistence. J. Exp. Med. 209, 61-75. doi: 10.1084/jem. 20100388

Siavoshian, S., Abraham, J. D., Thumann, C., Kieny, M. P., and Schuster, C. (2005). Hepatitis C virus core, NS3, NS5A, NS5B proteins induce apoptosis in mature dendritic cells. J. Med. Virol. 75, 402-411. doi: 10.1002/jmv. 20283

Smith, D. B., Bukh, J., Kuiken, C., Muerhoff, A. S., Rice, C. M., Stapleton, J. T., et al. (2014). Expanded classification of hepatitis $C$ virus into 7 genotypes and 67 subtypes: updated criteria and genotype assignment web resource. Hepatology 59, 318-327. doi: 10.1002/hep.26744

Stumptner-Cuvelette, P., Morchoisne, S., Dugast, M., Le Gall, S., Raposo, G., Schwartz, O., et al. (2001). HIV-1 Nef impairs MHC class II antigen presentation and surface expression. Proc. Natl. Acad. Sci. U.S.A. 98, 12144-12149. doi: $10.1073 /$ pnas. 221256498

Swadling, L., Klenerman, P., and Barnes, E. (2013). Ever closer to a prophylactic vaccine for HCV. Expert Opin. Biol. Ther. 13, 1109-1124. doi: 10.1517/14712598.2013.791277

Tardif, K. D., and Siddiqui, A. (2003). Cell surface expression of major histocompatibility complex class I molecules is reduced in hepatitis C virus subgenomic replicon-expressing cells. J. Virol. 77, 11644-11650. doi: 10.1128/JVI.77.21.11644-11650.2003 
Thimme, R., Oldach, D., Chang, K. M., Steiger, C., Ray, S. C., and Chisari, F. V. (2001). Determinants of viral clearance and persistence during acute hepatitis C virus infection. J. Exp. Med. 194, 1395-1406. doi: 10.1084/jem.194.10.1395

Thoens, C., Berger, C., Trippler, M., Siemann, H., Lutterbeck, M., Broering, R., et al. (2014). KIR2DL3+NKG2A-natural killer cells are associated with protection from productive hepatitis $\mathrm{C}$ virus infection in people who inject drugs. J. Hepatol. 61, 475-481. doi: 10.1016/j.jhep.2014.04.020

Thomas, D. L., Thio, C. L., Martin, M. P., Qi, Y., Ge, D., O’Huigin, C., et al. (2009a). Genetic variation in IL28B and spontaneous clearance of hepatitis C virus. Nature 461, 798-801. doi: 10.1038/nature08463

Thomas, R., Apps, R., Qi, Y., Gao, X., Male, V., O’HUigin, C., et al. (2009b). HLA-C cell surface expression and control of HIV/AIDS correlate with a variant upstream of HLA-C. Nat. Genet. 41, 1290-1294. doi: 10.1038/ ng.486

Torresi, J., Johnson, D., and Wedemeyer, H. (2011). Progress in the development of preventive and therapeutic vaccines for hepatitis C virus. J. Hepatol. 54, 12731285. doi: 10.1016/j.jhep.2010.09.040
Conflict of Interest Statement: The authors declare that the research was conducted in the absence of any commercial or financial relationships that could be construed as a potential conflict of interest.

Received: 08 July 2014; accepted: 12 September 2014; published online: 13 October 2014.

Citation: John M and Gaudieri S (2014) Influence of HIV and HCV on T cell antigen presentation and challenges in the development of vaccines. Front. Microbiol. 5:514. doi: 10.3389/fmicb.2014.00514

This article was submitted to Microbial Immunology, a section of the journal Frontiers in Microbiology.

Copyright (c) 2014 John and Gaudieri. This is an open-access article distributed under the terms of the Creative Commons Attribution License (CC BY). The use, distribution or reproduction in other forums is permitted, provided the original author(s) or licensor are credited and that the original publication in this journal is cited, in accordance with accepted academic practice. No use, distribution or reproduction is permitted which does not comply with these terms. 